Review

\title{
Bioactive Peptides: Applications and Relevance for Cosmeceuticals
}

\author{
Tamyres Nassa Lima and Carla Aparecida Pedriali Moraes * \\ Laboratório de Pesquisa, Tecnologia em Cosméticos, FATEC Diadema-Luigi Papaiz, \\ 09931-390 Diadema, SP, Brazil; tamyres.nassa@hotmail.com \\ * Correspondence: capedriali@hotmail.com; Tel.: +55-011-4092-2328
}

Received: 26 January 2018; Accepted: 1 March 2018; Published: 5 March 2018

\begin{abstract}
Peptides found in skin can act by different mechanisms of action, being able to function as epidermal or nervous growth factors or even as neurotransmitters. Due to the vast functionality of these compounds, there is growing research on bioactive peptides aimed at investigating their uses in products developed for stimulating collagen and elastin synthesis and improving skin healing. Thus, a literature search on applications of the most common bioactive peptides used in cosmeceuticals was carried out. There is a lack of proper reviews concerning this topic in scientific literature. Nine peptides with specific actions on body and facial dysfunctions were described. It could be noted while searching scientific literature that studies aimed at investigating peptides which prevent aging of the skin are overrepresented. This makes searching for peptides designed for treating other skin dysfunctions more difficult. The use of biomimetic peptides in cosmetic formulations aimed at attenuating or preventing different types of skin dysfunctions is a topic where information is still lackluster. Even though research on these compounds is relatively common, there is still a need for more studies concerning their practical uses so their mechanisms of action can be fully elucidated, as they tend to be quite complex.
\end{abstract}

Keywords: bioactive peptides; growth factor; neuropeptides

\section{Introduction}

Techniques aimed at extracting, isolating, characterizing, and synthetizing molecules, as well as techniques for the advanced study of molecular structures, were greatly improved after the second half of the last century. As a result, bioactive peptides or biomimetic peptides were brought to light in the current knowledge. Several peptides with remarkable biological activity were synthetized in the last few years. They can be used in areas ranging from cosmetics, therapeutics, and immunology to even food sciences [1]. Peptides account for $10 \%$ of the sales of pharmaceutical companies, which amounts to US $\$ 25$ billion; the commercialization of peptides has been increasing faster than that of small molecules [2]. Up to 2017, the global cosmeceutical market was estimated to have generated around US $\$ 42.8$ billion [3].

In this review, emphasis was given to synthetic peptides that are used in cosmeceutical formulations, which can be named either as bioactive, biomimetic, or topical peptides.

Peptides are short chains of amino acids. Some occur naturally in the human body and are known for playing several biological roles, especially as signaling/regulating molecules in a variety of physiological processes, including defense, immunity, stress, growth, homeostasis, and reproduction $[4,5]$. As examples, there are vasodilators, vasoconstrictors, and other substances that act upon cell metabolism:

(a) Substance $P$ can be found in the epidermis, a dipeptide with 11 amino acids that acts as a potent vasodilator contributing to the balance between cell differentiation and cell renewal [6,7]; 
(b) Peptides somatostin (SOM) and neuropeptide Y found in the skin (NPY-family of endocrine neurotransmitter peptides) play a role on the vascular tonus of the skin by causing vasodilation (by promoting the release of histamine) and vasoconstriction, respectively [6,7];

(c) Adipocytes present in the hypodermis are capable of releasing bioactive peptides, called adipocytokines, such as interleukin-6 (IL-6), leptin, resistin, tumor necrosis factor $\alpha$ (TNF- $\alpha$ ), acylation stimulating protein (ASP), and adiponectin [8];

(d) Insulin can be considered an example of a polypeptide which acts on cell metabolism, as it facilitates the entry of glucose to the cell interior and interacts with hepatocytes, muscular cells, and adipocytes [9].

Biomimetic peptides, on the other hand, are compounds which have an identical amino acid sequence to physiological peptides (oligopeptides with a sequence ranging from 10 to 15 amino acids), but are synthetized biotechnologically. They mimic the action of growth factors and cytokines by interacting with their receptors, leading to clinical effects such as the slowing of aging [10]. Examples of biomimetic peptides include acetyl decapeptide-3 (Rejuline), oligopeptide-24 (CG-EGP3), oligopeptide-34 (CG-TGP2), and oligopeptide-72 (Boostrin).

Bioactive or topical peptides are also synthetic compounds, but they consist of modified amino acid chains, which improve an already existing physiological function, such as increasing skin permeability, stability, solubility, and better interaction with cell receptors [5,11-13]. Also, several natural physiological processes are signaled and modulated exclusively by interaction with specific amino acid sequences found in certain peptides and protein fragments. Thus, in a technological context, bioactive peptides are becoming increasingly promising as cosmeceuticals with clinical applications in different skin conditions [12,13].

The multiple applications of these synthetic compounds, either biomimetic or bioactive, provide treatment options when used in formulations designed for topical applying, preventing, or attenuating the clinical aspects of skin damaged by dysfunctions: aging, hyperpigmentation, increase of body fat, and wrinkle development $[10,12,13]$. These peptides can also stimulate the synthesis of collagen and elastin $[10,11,14]$, improve wound healing $[15,16]$, increase fibroblast proliferation $[10,11,14]$, and act as growth factors [17] or even as tensioning and tightening agents $[10,11,14]$.

Bioactive peptides can be classified according to their mechanism of action in signal, carrier, and neurotransmitter inhibitor peptides [5,11].

The goal of this study was to carry out a literature review on bioactive peptides aiming to describe some of their mechanisms of action and possible applications in cosmetic products. This review might contribute to future research by summarizing relevant information and making it readily available for professionals and researchers interested in the subject.

\section{Signal Peptides}

Signal peptides have a structure which can be divided in three different domains: a positively-charged amino-terminal domain (region $n, 1-5$ long residues); a hydrophobic central domain (region h, 7-15 residues); and a polar carboxyl-terminal domain (region c, 3-7 residues). This class of peptides is very important due to its ability to open protein channels which allow the translocation of synthetized proteins to their specific site of action [5,11].

Vastly used as active compounds in products aimed at preventing aging, signal peptides are a class of peptides capable of stimulating skin fibroblasts, leading to an increased production of collagen and elastic fibers. They can also act as growth factors, as they activate protein kinase C, which is the major factor responsible for cell growth and migration. Such stimulus occurs whenever the peptide has its amino acids aligned in a specific pattern, as is the case with the sequence valine-glycine-valine-alanine-proline-glycine (VGVAPG), commercially named palmitoyl oligopeptide $^{\circledR}$, as elastin-derived peptides bind to cytoplasmic fibroblast receptors $[5,11,12,14]$. 


\subsection{Heptapeptide Acetyl-DEETGEF-OH}

Heptapeptide Acetyl-DEETGEF-OH (Perfection Peptide P7 ${ }^{\mathrm{TM}}$ ), a signal peptide, acts by protecting cell DNA by stimulating Nrf2-dependant antioxidant enzymes. This heptapeptide is a competitive inhibitor of the repression factor Keap1 which acts directly upon transcription factor Nrf2, responsible for scavenging free radicals. Water in oil emulsions developed with the aid of nanotechnology can contain a very minimal amount of the peptide $(0.0014 \%)$ initially dispersed in shea butter. After exposure to ultraviolet radiation (UV) for two hours, Langerhans cells were reduced in size and more cells were "sunburned" in the skin of subjects treated with placebo. In comparison, subjects that had the formulation containing the heptapeptide had the depletion of skin cells reduced by $6 \%$, and the DNA damage of the affected cells was reduced by $20 \%$. This study aimed to prove the efficacy of the formulation, and was carried out by Suter and collaborators (2016) [18]. It is commercialized by Mibelle Biochemistry Group and its INCI (International Nomenclature of Cosmetic Ingredients) name is acetyl sh-heptapeptide-1 (and) hydrogenated lecithin (and) glycerin (and) Butyrospermum parkii (shea) butter (and) phenethyl alcohol (and) ethylhexylglycerin (and) aqua [19].

\subsection{Oligopeptide- 68}

Oligopeptide-68 ( $\beta$-WHITE ${ }^{\mathrm{TM}}$, sequence Arg-Asp-Gly-Gln-Ile-Leu-Ser-Thr-Trp-Tyr) is a whitening agent used in cosmetics on skins affected by melasma. It inhibits the actions of microphthalmia-associated transcription factor (MITF), a regulator of melanocyte differentiation, by reducing its tyrosinase activity and "slowing down" key enzymes of the pigmentation process. As a signal peptide, it interacts well with cells when used at concentrations of 1.0-2.5\%. Studies were carried out comparing the effects of hydroquinone (HQ) and of oligopeptide- 68 associated with diacetyl boldine (DAB), a compound capable of stabilizing tyrosinases. Different oil in water emulsion formulations (one containing HQ and another containing peptide and DAB) were applied to the skin of 40 volunteers; the subjects were assessed on the 6th and 12th week of treatment after controlled exposure to radiation. Of the initial subjects, 38 completed the study. The clarifying effects were considered significant, moderate, or slight for $2.6 \%, 76.3 \%$, and $21.1 \%$ of the subjects treated with the formulation containing the oligopeptide, respectively, and these values are higher than those observed in subjects treated with creams containing HQ at concentrations of $2 \%$ and $4 \%$ [20]. This whitening agent is becoming a frequent subject of study in the research and development of cosmetics. It is commercialized by Biotec, part of the AQIA Industrial Chemistry group, under INCI name water (and) butylene glycol (and) hydrogenated lecithin (and) sodium oleate (and) oligopeptide-68 (and) disodium EDTA [21].

\subsection{Tripeptide- 41}

Adipocytes found in the hypodermis contain a high amount of lipids, and each is connected to a number of capillary vessels. When hyperplasia and hypertrophy of such adipocytes occur, remodeling of the surrounding capillaries and neovascularization must take place, otherwise the lipodystrophy that follows causes the formation of wrinkles which lead to cellulitis [22].

Tripeptide-41 (Lipoxyn ${ }^{\circledR}$ ) activates NF-kB, a nuclear transcription factor which promotes the synthesis of tumor necrosis factor $\alpha(\mathrm{TNF} \alpha)$, a cytokine capable of triggering lipolysis. The peptide also reduces the expression of $\mathrm{C} / \mathrm{EBP}$, a transcription factor essential for adipocyte differentiation; this factor, when bound to PPAR $\gamma$, contributes to hyperplasia of adipose tissue. The peptide also increases the concentration of cAMP, an important intracellular signaling factor that causes lipolysis by promoting the hydrolysis of lipids into triglycerides [22,23].

This peptide is also a signal peptide, but there are few completed studies which report on its efficacy. It is commercialized by PharmaSpecial ${ }^{\circledR}$, represented by Caregen, a leading global company in the market of peptides and growth factors. Studies carried out by the product developers have been published. One such study, for example, was carried out in vivo, describing the application of an 
emulsion containing $5 \%$ of the peptide once a week for 8 weeks, and the volunteer reported having their waist circumference reduced by $5 \mathrm{~cm}$ [23].

\section{Carrier Peptides}

Carrier peptides are responsible for transporting and stabilizing oligoelements such as copper and manganese, carrying them to the skin and allowing their intake by epithelial cells [5,11]. Copper is one of the metals which can be transported by such peptides, playing a role on wound healing as well as being a cofactor for enzymes lysyl oxidase, tyrosinase, and superoxide dismutase, which are essential for collagen synthesis, melanogenesis, and superoxide dismutation (antioxidant action) [24]. Also, these peptides can stimulate key enzyme actions; an example is the tripeptide-copper complex glycyl-L-histidyl-L-lysine-Cu ${ }^{2+}$ (copper peptide GHK-Cu or copper tripeptide 1), which not only transports copper, but also increases the tissue levels of metalloproteinases, enzymes responsible for degrading the basic components of the extracellular matrix $[15,24,25]$.

The effects of GHK-Cu upon metalloproteinase synthesis (MMP-2) by skin fibroblasts in culture were demonstrated by Siméon and collaborators (2000) [24]. In their study, cultivated fibroblasts treated with GHK-Cu showed increased MMP-2 levels. This was evidenced by increased levels of MMP2 mRNA and increased secretion of tissue metalloproteinase inhibitors (TIMP-1 and TIMP-2). GHK-Cu is also responsible for the remodeling of the extracellular matrix, as it modulates the expression of MMP by acting directly in wound fibroblasts.

A study carried out by Finkley and collaborators (2005) [25] describes the application of facial creams containing GHK-Cu for 12 weeks on 71 volunteers aged between 50 and 59 years, and the results demonstrated a visible reduction of the effects of aging. In another study by the same authors, they describe the application of the formulation on the eyes of 41 volunteers using similar experimental conditions. At the same time, placebo and controls containing vitamin $\mathrm{K}$ were also applied to the subjects. In both studies it was demonstrated that the cream containing GHK-Cu improved the elasticity and tightness of the skin, and also reduced fine lines and deep wrinkles.

\section{Neurotransmitter Inhibitor Peptides}

These peptides are capable of increasing minimal muscle activity. For muscle contraction to occur, vesicles containing neurotransmitter acetylcholine must be released in neuromuscular junctions and interact with SNARE complexes (soluble N-ethylmaleimide-sensitive factor activating protein receptor). This process is modulated by a receptor protein, SNAP-25, which is a membrane protein that becomes associated with the vesicle, and directly regulates binding and vesicle fusion involving the SNARE complex. Some peptides possess structural similarities to proteins SNAP-25 in the SNARE complexes, and compete for the binding sites of these complexes, leading to the destabilization of their structure and preventing the release of acetylcholine at nervous endings, modulating the actions of this neurotransmitter $[6,11,26]$.

Peptides of this class are used in anti-aging cosmetics due to their attenuating actions on the formation of wrinkles as they promote the involuntary movement of facial muscles. These peptides have been shown to specifically inhibit neurosecretion, and therefore have been called neurotransmitter inhibitor peptides [6,11].

\subsection{Acetyl Hexapeptide-3 (Argireline $\left.{ }^{\circledR}\right)$}

The bioactive peptide of sequence Acetyl-Glu-Glu-Met-Gln-Arg-ArgNH $\mathrm{H}_{2}$, known as acetyl hexapeptide-3, is a compound similar to botulinum toxin A, but it lacks the $\mathrm{N}$-terminal domain of protein SNAP-25, competing for binding to the SNARE complexes modulating its formation, which inhibits the formation of acetylcholine and as a consequence attenuates muscle contraction. The peptide also attenuates wrinkle development due to involuntary skin movements. The action of botulinum toxin A is similar to that of a protease, cleaving protein SNAP-25 from the SNARE complex. This results in the inhibition of the release of acetylcholine [26,27]. 
In vivo tests using four lobsters with exposed muscular mass were carried out; the animals were submerged in solutions containing different concentrations of the active peptide $(0,10,15$, and $20 \mu \mathrm{M})$, and it could be verified that the amplitude of excitatory post-synaptic potentials was progressively reduced, inhibiting the action of other proteins which are vital for muscle movement [28].

In another experiment carried out with 20 human subjects for 30 days, the skin application of oil in water emulsions containing the peptide caused a reduction of wrinkle depth by $59 \%$ and $71 \%$ and size by $41 \%$ and $50 \%$ for dry and oily skins, respectively, in comparison with placebo controls. An area of $1.5 \mathrm{~cm}^{2}$ of skin was subjected to application, which occurred twice a day in a standardized manner. The equipment Clinipro Antiaging SD alongside an IMAGE DB system was used for determination of wrinkle depth and width [29].

This peptide is commercialized by Galena ${ }^{\circledR}$, a pioneer in the field of distribution of raw materials to pharmaceutical companies, and has the INCI name aqua (and) acetyl hexapeptide-8 (and) phenoxyethanol (and) methylparaben (and) ethylparaben (and) butylparaben (and) propylparaben (and) isobutylparaben [30].

\subsection{Acetyl Tripeptide-30 Citrulline and Pentapeptide-18}

Vanistryl ${ }^{\circledR}$ is the commercial name of formulations containing acetyl tripeptide-30 citrulline and pentapetide-18, which are bioactive peptides used in wrinkle smoothing formulations that act in synergism modulating muscular tension and inhibiting matrix metalloproteinases (MMPs) when applied to the skin. Acetyl tripeptide-30 citrulline (Sequence: Lys- $\alpha$-Asp-Ile-Citrulline) is a signal peptide, while pentapeptide-18 (Sequence: Tyr-D-Ala-Gly-Phe-Leu) is a neurotransmitter inhibitor peptide [31,32].

The application of water in oil emulsions to the skin of 12 volunteers with recent stretch marks at the waist and thighs, twice a day for 30 and 60 days and containing these active components at a concentration of $5 \%$, improved the visual aspects of wrinkles by $38.89 \%$, tightness by $70.83 \%$, softness by $133.33 \%$, touch perception by $28.61 \%$, and color by $50.58 \%$. Stretch marks were also softened. Complete quantitative and qualitative clinical evaluations were carried out by dermatologists before treatment and after 30 and 60 days of treatment. Surface studies (tightness and drying) were performed with the aid of a Visioscan VC98; color studies made use of Mexameter MX18; and skin elasticity analysis was carried out using Soft Mini Three equipment [32].

As acetyl hexapeptide-3, this peptide is commercialized by Galena ${ }^{\circledR}$ and by LIPOTEC $^{\circledR}$, a laboratory which has developed several technological compounds, mostly bioactive peptides. Its INCI name is water, caprylyl/capryl glucoside, lecithin, glycerin, Pseudoalteromonas ferment extract, acetyl tripeptide-30 citrulline, pentapeptide-18, xanthan gum, caprylyl glycol [32].

\section{Neurocosmetics}

Neurocosmetics are cosmeceuticals which contain synthetic neuropeptides that interact with the nervous system through skin mediators [13,33]. These compounds can play a role in skin homeostasis by activating or inhibiting such mediators. Skin responses carried out by mediators are regulated by a neuroendocrine system found in the skin capable of initiating adaptation mechanisms through quick pathways (neural pathways) or slow pathways (humoral pathways), acting at both local and systemic levels $[33,34]$. Neurocosmetics can act in the central nervous system, being capable of stimulating the nerve endings of the skin, sending pleasure and well-being "feelings" to the hypothalamus, and causing the release of specific substances on the skin which improve the aspect of skin relief [13].

Skin cells release growth factors and proteins that bind insulin, which are synthetized from proopiomelanocortine (POMC), catecholamines, steroidal hormones, vitamin D, eicosanoids from fat acids, and retinoids from diet carotenoids. Skin has developed an autonomous system that responds to local and peripheral stress, which functions by making use of neurotransmitters and hormone peptides in a manner similar to the hypothalamus-hypophysis-adrenal axis [13,33]. 
POMC peptides are synthetized by melanocytes, keratinocytes, microvascular endothelial cells, annex epithelial cells, mastocytes, Langerhans cells, fibroblasts, and immune cells, such as monocytes and macrophages. POMC, as a precursor protein, leads to the synthesis of several biologically active peptides through a series of enzymatic steps, which are often specific to each tissue, resulting in the formation of melanocyte stimulator hormones (MSHs), corticotrophin (ACTH), and ß-endorphin [13,33,35].

Fatemi and collaborators (2016) [36] demonstrated that a peptide derived from POMC, bPOMC, has anti-inflammatory properties and does not disrupt melanogenesis. When skin is exposed to capsaicin, biomimetic peptides are capable of attenuating inflammation by preventing the release of substance $P$ and the actions of IL-8 and IL-1 [34-36].

The same research group, in a double-blind study, employed 56 healthy volunteers with sensitive skin (36 male and 20 female, aged 26 to 40 years) divided into two groups of 28 volunteers each. Both groups received a facial formulation $(0.1 \mathrm{~g})$ containing bPOMC, which was used on the right side of the face, and a placebo formulation, which was used on the left side, applied on clean cheeks from the nasolabial to the outer cheek areas with circular movements twice a day for 14 days. The sensorial irritation test (pinching, burning, and itching) was carried out with the application of capsaicin at $3 \times 10^{-4 \%}$ for $5 \mathrm{~min}$ [36]. After the testing period, the authors verified that the group treated with the formulation containing bPOMC had fewer irritation sensations when compared to the control group, further indicating that biomimetic peptides, such as bPOMC, when used in skin formulations, can significantly reduce symptoms from contact dermatitis, which is an issue for several consumers of cosmetics and topic formulations [36].

\section{Happybelle-PE ${ }^{\circledR}$}

This compound is often associated with liposomes, made of a complex of phyto-endorphins responsible for stimulating fibroblast and keratinocyte proliferation, resulting in wrinkle attenuation and increased cell renewal, revitalization, and hydration [37]. There are still no conclusive studies on the efficacy of this peptide. It is commercialized by Mibelle AG Biochemistry, and its INCI name is lecithin (and) Vitex agnus-castus extract (and) glycerin (and) ascorbyl tetraisopalmitate (and) tocopherol (and) olus oil / vegetable oil (and) cyclodextrin (and) alcohol (and) water [37].

\section{Safety Assessment of Bioactive Peptides Used in Cosmetics}

Some bioactive peptides have already been studied regarding their safety both in vitro and in vivo. According to the FDA (Food and Drug Administration), up to 2012, palmitoyl-like peptides have been the most extensively tested molecules regarding safety so far, as they are also commercialized in cosmetic products [38].

The bioactive acetyl hexapeptide- 3 has been studied to some extent. Maia Campos and collaborators (2014) [39] evaluated the safety of this peptide by making use of the primary skin irritation test and the patch test. They describe having used a hypoallergenic adhesive tape (50 $\mathrm{mm}^{2}$ area) applied a single time at occlusive conditions to the dorsal area of 27 volunteers (aged between 20 to 59 years) of phototypes II and IV. After $48 \mathrm{~h}$, the tape was removed and the visual evaluation of the result was performed when the erythema was no longer was perceptible; no irritation reactions were caused after $48 \mathrm{~h}$ of occlusive contact. The research group of Blanes-Mira and collaborators (2002) [26], also demonstrated by means of the skin irritation test, reported that the bioactive acetyl hexapeptide-3 is safe to use in an analysis that used botulinum neurotoxin as a control.

Another study of skin irritation carried out with peptide $\mathrm{GHK}-\mathrm{Cu}$ at a volume of $0.5 \mathrm{~mL}$ in an area of $6 \mathrm{~cm}^{2}$ using three male rabbits and a covering tape for $24 \mathrm{~h}$, with readings conducted at 24 and $72 \mathrm{~h}$, demonstrated that this active component is not a skin irritant under the tested conditions $(\mathrm{PII}=0.3)[40,41]$. 


\section{Conclusions}

Bioactive peptides are becoming increasingly popular in the research and development of cosmetic formulations aimed at treating damaged and dysfunctional skin. Several companies such as PharmaSpecial $^{\circledR}$, Galena $^{\circledR}$, Biotec ${ }^{\circledR}$, Lipotec $^{\circledR}$, and Silab ${ }^{\circledR}$ are investing in technologically innovative bioactive peptides, focusing on signal peptides and neurotransmitter inhibitor peptides. Bioactive peptides amount to $10 \%$ of all sales of pharmaceutical companies.

Any cosmetic products which contain bioactive peptides in their formulations must be submitted to efficacy and safety tests in order to be approved by the National Health Surveillance Agency (ANVISA) and thus allowed to be commercialized. However, there is a lack of published studies on such peptides; the most commonly studied peptides are synthetized from palmitoyl, such as palmitoyl oligopeptide, palmitoyl pentapeptide-4, and palmitoyl tetrapeptide-7, and such studies are generally focused on wrinkle attenuation and skin filling.

It was observed that the majority of research studies are focused on the development of anti-aging actives, and there is still room for research to be carried out to evaluate other functions of these actives. Studies reporting on the efficacy of bioactive peptides with specific functions and clarifying their mechanisms of action, mostly regarding their actions upon the attenuation of stretch marks and cellulites, are few, which makes it difficult to search for specific functions of bioactive peptides.

Author Contributions: Tamyres Nassa Lima and Carla Aparecida Pedriali Moraes analyzed the data; Tamyres Nassa Lima wrote the final manuscript and Carla Aparecida Pedriali Moraes revised it.

Conflicts of Interest: The authors declare no conflict of interest.

\section{References}

1. Machado, A.; Liria, C.W.; Proti, P.B.; Remuzgo, C.; Miranda, M.T.M. Síntese química e enzimática de peptídeos: Princípios e aplicações. Quim. Nova 2004, 5, 781-789. [CrossRef]

2. Peptide Therapeutics Market (by Applications, by Route of Administration, and by Marketing Status) -Global Industry Analysis, Size, Share, Growth, Trends and Forecast 2014-2020. April 2017. Available online: http:/ / www.transparencymarketresearch.com/pressrelease/peptide-therapeutics-market.htmd (accessed on 1 October 2017).

3. Global Cosmeceuticals Market Outlook 2020. RNCOS E-Services Pvt. Ltd., July 2017. Available online: http:/ / www.giiresearch.com/report/rnc263147-global-cosmeceutical-market-outlook.html (accessed on 1 October 2017).

4. Linder, J. The science behind peptides. Plast. Surg. Nurs. 2012, 32, 71-72. [CrossRef] [PubMed]

5. Zhang, L.; Falla, T.J. Cosmeceuticals and peptides. Clin. Dermatol. 2009, 27, 485-494. [CrossRef] [PubMed]

6. Gaspar, P.K. Neuropeptides in the skin. An. Bras. Dermatol. 2003, 78, 483-498.

7. Scholzen, T.; Armstrong, C.; Burnett, N.; Luger, T.; Olerud, J.; Ansel, J. Neuropeptides in the skin: Interactions between the neuroendocrine and the skin immune systems. Exp. Dermatol. 1998, 7, 81-96. [CrossRef] [PubMed]

8. Guimaraes, D.E.D.; Sardinha, F.L.C.; Mizurini, D.M.; Carmo, M.G.T. Adipocinas: Uma nova visão do tecido adipose. Rev. Nutr. 2007, 20, 549-559. [CrossRef]

9. Claeys, I.; Simonet, G.; Poels, J.; Loy, T.V.; Vercamme, L.; Loof, A.; Broeck, J.V. Insulin-related peptides and their conserved signal transduction pathway. Peptides 2002, 23, 807-816. [CrossRef]

10. Gazitaeva, Z.I.; Drobintseva, A.O.; Chung, Y.; Polyakova, V.O.; Kvetnoy, I.M. Cosmeceutical product consisting of biomimetic peptides: Antiaging effects in vivo and in vitro. Clin. Cosmet. Investig. Dermatol. 2017, 10, 11-16. [CrossRef] [PubMed]

11. Pai, V.V.; Bhandari, P.; Shukla, P. Topical peptides as cosmeceuticals. Indian J. Dermatol. Venereol. Leprol. 2017, 83, 9-18. [CrossRef] [PubMed]

12. Fields, K.; Falla, T.J.; Rodan, K.; Bush, L. Bioactive peptides: Signaling the future. J. Cosmet. Dermatol. 2009, 8, 8-13. [CrossRef] [PubMed]

13. Lintner, K.; Mas-Chamberlin, C.; Mondon, P.; Peschard, O.; Lamy, L. Cosmeceuticals and active ingredients. Clin. Dermatol. 2009, 27, 461-468. [CrossRef] [PubMed] 
14. Gorouhi, F.; Maibach, H. Role of topical peptides in preventing or treating aged skin. Int. J. Cosmet. Sci. 2009, 31, 327-345. [CrossRef] [PubMed]

15. Siméon, A.; Monier, F.; Emonard, H.; Gillery, P.; Birembaut, P.; Hornebeck, W.; Maquart, F.X. Expression and activation of matrix metalloproteinases in wounds: Modulation by the tripeptide-copper complex glycyl-L-histidyl-L-lysine-Cü ${ }^{2+}$. J. Investig. Dermatol. 1999, 112, 957-964. [CrossRef] [PubMed]

16. Netto, J.C.; Mendonça, R.J. Aspectos celulares da cicatrização. An. Bras. Dermatol. 2009, 84, $257-262$.

17. Carpenter, G.; Cohen, S. Epidermal growth factor. J. Biol. Chem. 1990, 265, 7709-7712. [PubMed]

18. Suter, F.; Schmid, D.; Wandrey, F.; Zulli, F. Heptapeptide-loaded solid lipid nanoparticles for cosmetic anti-aging applications. Eur. J. Pharm. Biopharm. 2016, 108, 304-309. [CrossRef] [PubMed]

19. MIBELLE GROUP BIOCHEMISTRY. Paris: PERFECTION PEPTIDE-P7 ${ }^{\circledR}$. Available online: https:// mibellebiochemistry.com/products/perfectionpeptide-p7/ (accessed on 28 October 2017).

20. Pratchyapurit, W.O. Combined use of two formulations containing diacetyl boldine, TGF- $\beta 1$ biomimetic oligopeptide-68 with other hypopigmenting/exfoliating agents and sunscreen provides effective and convenient treatment for facial melasma. Either is equal to or is better than $4 \%$ hydroquinone on normal skin. J. Cosmet. Dermatol. 2016, 15, 95-101.

21. BIOTEC. São Paulo: $\beta$. WHITE ${ }^{\mathrm{TM}}$. Available online: http://www.biotecdermo.com.br/b-white/ (accessed on 31 August 2017).

22. Halbe, H.W.; Cunha, D.C. O Excesso do órgão adiposo. Diagn. Tratamento 2008, 13, 153-160.

23. PHARMASPECIAL. São Paulo: LIPOXYN ${ }^{\circledR}$. Available online: http://www.pharmaspecial.com.br/media/ produtos/_lit_lipoxyn.pdf (accessed on 30 June 2017).

24. Siméon, A.; Emonard, H.; Hornebeck, W.; Maquart, F.X. The tripeptide-copper complex glycyl-L-histidyl-Llysine- $\mathrm{Cu}^{2+}$ stimulates matrix metalloproteinase-2 expression by fibroblast cultures. Life Sci. 2000, 67, 2257-2265. [CrossRef]

25. Finkley, M.; Appa, Y.; Bhandarkar, S. Copper peptide and skin. In Cosmeceuticals and Active Cosmetics: Drugs vs. Cosmetics; Elsner, P., Maibach, H., Eds.; Marcel Dekker Press: New York, NY, USA, 2005; pp. 549-563.

26. Blanes-Mira, C.; Clemente, J.; Jodas, G.; Gil, A.; Fernández-Ballester, G.; Ponsati, B.; Gutierrez, L.; Pérez-Payá, E.; Ferre-Montiel, A. A synthetic hexapeptide (Argireline) with antiwrinkle activity. Int. J. Cosmet. Sci. 2002, 24, 303-310. [CrossRef] [PubMed]

27. Wang, Y.; Wang, M.; Xiao, S.; Pan, P.; Li, P.; Huo, J. The anti-wrinkle efficacy of argireline, a synthetic hexapeptide, in Chinese subjects: A randomized, placebo-controlled study. Am. J. Clin. Dermatol. 2013, 14, 147-153. [CrossRef] [PubMed]

28. Kang, A.; Shults, A.; Zhao, Y. Argireline decreases EPSP amplitude over time, and increases paired-pulse facilitation in a dose-dependent manner. Eur. J. Neurosci. 2015, 15, 17-23.

29. Ruiz, M.A.; Clares, B.; Morales, M.E.; Gallardo, V. Evaluation of the anti-wrinkle efficacy of cosmetic formulations with an anti-aging peptide (Argireline ${ }^{\circledR}$ ). ARS Pharm. 2010, 50, 168-176.

30. GALENA. São Paulo: ARGIRELINE ${ }^{\circledR}$. Available online: http://www.pharmakondf.com.br/Pharmakon/ arquivos/INSUMOS_FARMACEUTICOS/A/6213_-_IC_-_ARGIRELINE.pdf (accessed on 25 June 2017).

31. Petit, J.L.V.; Gonzalez, R.D.; Botello, A.F. Nanocapsules Containing Microemulsions. U.S. Patent 20,130,216,596, 22 August 2013.

32. GALENA. São Paulo: VANISTRYL®. Available online: http://www.farmacianaturalfarma.com.br/noticias / 7ae84ef6051d941223a415ddf24b38d3.pdf (accessed on 25 April 2017).

33. Slominski, A.; Wortsman, J. Neuroendocrinology of the skin. Endocr. Rev. 2000, 21, 457-487. [CrossRef] [PubMed]

34. Fuller, R.W.; Conradson, T.B.; Dixon, C.M.; Crossman, D.C.; Barnes, P.J. Sensory neuropeptide effects in human skin. Br. J. Pharmacol. 1987, 92, 781-788. [CrossRef] [PubMed]

35. Millington, G.W. Proopiomelanocortin (POMC): The cutaneous roles of its melanocortin products and receptors. Clin. Exp. Dermatol. 2006, 31, 407-412. [CrossRef] [PubMed]

36. Fatemi, S.A.; Dehkordi, A.J.; Haijhashemi, V.; Mahabadi, A.A. Biomimetic proopiomlanocortin suppress capsaicin-induced sensory irritation in humans. Res. Pharm. Sci. 2016, 11, 484-490. [PubMed]

37. MIBELLE GROUP BIOCHEMISTRY. Paris: HAPPYBELLE-PE ${ }^{\circledR}$. Available online: https://mibellebiochemistry. com/products/happybelle-pe/ (accessed on 26 December 2017).

38. Safety Assessment of Palmitoyl Oligopeptides as Used in Cosmetics. Available online: http://www.cirsafety.org/sites/default/files/palmit072012slr.pdf (accessed on 22 April 2017). 
39. Maia Campos, P.M.G.; Mercúrio, D.G.; Tadini, K.A. Acetyl hexapeptide-3 in a cosmetic formulation acts on skin mechanical properties-Clinical study. Braz. J. Pharm. Sci. 2015, 51, 901-909.

40. Safety Assessment of Tripeptide-1, Hexapeptide-12, Their Metal Salts and Fatty Acyl Derivatives, and Palmitoyl Tetrapeptide-7 as Used in Cosmetics. Available online: https: / /www.cir-safety.org/sites/default/ files/tripep062014final.pdf (accessed on 22 April 2017).

41. Pickart, L.; Lovejoy, S. Biological activity of human plasma copper-binding growth factor glycyl-L-histidyl-Llysine. Methods Enzymol. 1987, 147, 314-328. [PubMed] 